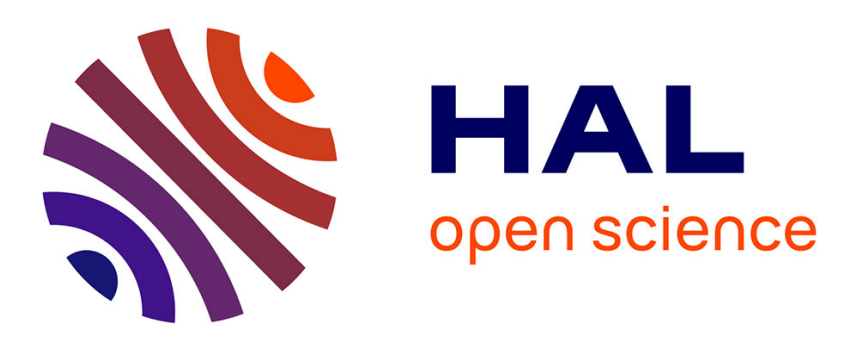

\title{
A Graftable Quaternary Ammonium Biocidal Polymer Reduces Biofilm Formation and Ensures Biocompatibility of Medical Devices
}

Houssam Bouloussa, Azzam Saleh-mghir, Claire Valotteau, Chahrazad Cherifi, Narjès Hafsia, Martine Cohen-solal, Charles Court, Anne-claude Crémieux, Vincent Humblot

\section{To cite this version:}

Houssam Bouloussa, Azzam Saleh-mghir, Claire Valotteau, Chahrazad Cherifi, Narjès Hafsia, et al.. A Graftable Quaternary Ammonium Biocidal Polymer Reduces Biofilm Formation and Ensures Biocompatibility of Medical Devices. Advanced Materials Interfaces, 2021, pp.2001516. 10.1002/admi.202001516 . hal-03155802

\section{HAL Id: hal-03155802 \\ https://hal.sorbonne-universite.fr/hal-03155802}

Submitted on 2 Mar 2021

HAL is a multi-disciplinary open access archive for the deposit and dissemination of scientific research documents, whether they are published or not. The documents may come from teaching and research institutions in France or abroad, or from public or private research centers.
L'archive ouverte pluridisciplinaire HAL, est destinée au dépôt et à la diffusion de documents scientifiques de niveau recherche, publiés ou non, émanant des établissements d'enseignement et de recherche français ou étrangers, des laboratoires publics ou privés. 
4

\section{INTRODUCTION:}

The use of large biomedical implants has demonstrated a decisive turn over the last 30 years with the popularization of hip and knee joint replacement (1). Fast aging in industrial societies, increased life expectancy and quality along with functional demands from the elder population account for the rise of both invasive and non-invasive procedures comprising biomaterial implantation (2). Substantial progress was made in terms of mechanical properties, biocompatibility, and biointegration resulting in excellent functional outcomes in multiple surgical specialties. On the other hand, there is to this date no consensus for an anti-infectious strategy in order to prevent biofilm formation on implanted surfaces. The consequences of nosocomial infections arising from surgical implants still represent a heavy burden on both patients and healthcare systems worldwide (3). In spite of the advancements of antisepsis procedures, a significant and fixed proportion of nosocomial infections are still reported (from 1 to $2 \%$ respectively for hip and knee joint replacement). Biofilm is an exopolysaccharidic matrix comprising bacteria with reduced antibiotic sensitivity and poor mechanical accessibility (4)(5)(6). Biofilm formation plays a major role in the failure of conservative treatments (antibiotic use, wound debridement and lavage) for implant-related infections (7). A common rule is to perform implant removal to treat biofilm-related infections if a proper conservative treatment has previously failed, which explains the high morbidity caused by the management of infections on implanted devices (8). This represents the rationale behind the development of coating strategies for the prevention of implant-related infections (9). Indeed, since the first stage of biofilm formation is believed to be bacterial adherence, there has been a tremendous enthusiasm about the development of new coatings and surface modifications aimed at repelling bacteria or killing bacteria on contact. Numerous in vitro studies showed the interest of biocidal polymers grafted on plastics or metals in the medical field (10). They target bacterial colonization, bacterial encapsulation or both. Polymer-based coatings may either reduce bacterial adherence or directly kill bacteria without altering the mechanical and thermic properties of implanted devices. The agents preventing bacterial colonization are antiadhesive polymers inhibiting bacterial adhesion (polyvinyl sodium sulfonate, polyethylene glycol, PEG) and biocidal substances such as antibiotic coatings and silver-impregnated surfaces. Currently, the most concerning drawbacks of antibacterial polymers which relies on antiadhesive effects are their transitory local efficacy, potential toxicity through progressive leaching and the low or absent bacteriostatic or bactericidal effect. Therefore, bactericidal polymeric agents have been introduced. The most used are high-density quaternary ammonium salts (chitosans (11)), 
49 50 51 52 53 54 55 56 57 58 59 60 61

phosphonium salts (12), sulfonium salts (13), pyridinium salts (14) and mono or biguanidium salts (15). These high-density cationic polymers feature a non-selective bacteria contact-killing effect (16). While they are extensively described in the literature, the biocidal mechanisms remain poorly detailed. In fact, most studies focused on killing mechanisms occurring in solutions of varying densities (18)(19) and not on grafted high-density QAP.

A novel ready-to-use and scalable QAP, Q-PVP (quaternized polyvinylpyridine) was synthesized in a methanolic solvent in a single step. The objective of the study was to characterize grafted titanium surfaces, measure their in vitro antibacterial activity quantitatively and qualitatively, assess biofilm inhibition and in vitro biocompatibility.

\section{MATERIAL AND METHODS:}

\section{1) Polymer synthesis}

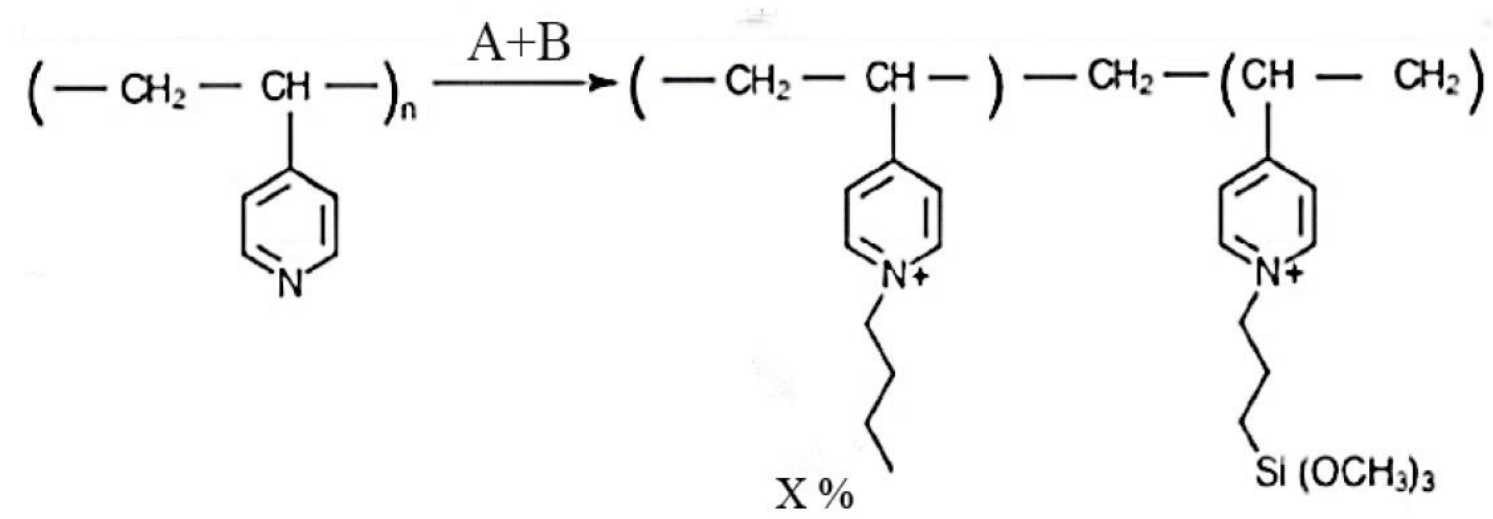

Figure 1. Quaternized polyvinylpyridine polymer synthesis

n: $1 \mathrm{Eq}$
A: iodopropyltrimethoxysilane, 20 to $50 \mathrm{mEq}$

B: 1 -bromobutane, $1 \mathrm{Eq}$

$\mathbf{x}$ depends on reaction time

A quaternized polyvinylpyridine (Q-PVP) statistical polymer was synthesized following the introduction of specific chains on the polymeric chain in a single-step reaction in boiling methanol. Five specific changes were carried out in the synthesis process. Polymers synthesized with no bromobutane chain were labelled Q-PVP-iodo. Reaction time also varied in order to modulate the ammonium quaternization rate. Polymers synthesized in 36h, 2 days and 4 days were respectively labelled Q-PVP-36h, Q-PVP-2days, Q-PVP-4days. When polyethylene 
glycol (PEG) replaced 1-bromobutane in the synthesis $(24 \mathrm{~h})$, the product was labelled Q-PVP-

63 PEG. The iodopropyltrimethoxysilane chain was used as a "hook" in order to immobilize the polymeric chain on the activated surface through a covalent linkage between the surface and the polymeric moiety. The butyl chain was used to quaternize the rest of the Q-PVP chain. A fixed 5\% proportion of iodopropyltrimethoxysilane was critical to reach storability of the polymer since higher proportions cause reticulation in volume and therefore prevent long-term storage.

\section{2) Polymer grafting}

$1 \mathrm{~cm}^{2}$ titanium plates $(99,6 \%$ purity, Goodfellow, Cambridge Ltd., Huntington, United Kingdom) were successively polished on 3 grains (P800, P2000 and P4000 grit paper using a Saphir 320, ATA GmbH, Mammelzen, Germany) for respectively 1 minute, 2 minutes and 3 minutes. Following abundant lavage and a 5-minute sonication process with distilled water in order to remove residual particles, the plates were placed in a piranha solution ( $96 \%$ sulfuric acid/30\% hydrogen peroxide (2/1, v/v) for two hours so as to obtain hydroxylation and surface chemical abrasion (hence forming activated surfaces). All plates were subsequently rinsed, sonicated in distilled water and dried under nitrogen flux. Polymer grafting was achieved either by one or six spin-coating rounds of a diluted $125 \mu \mathrm{L}$ polymer drop $(100 \mu \mathrm{L}$ polymer, $25 \mu \mathrm{L}$ distilled water) on activated titanium plates (40 seconds, $3000 \mathrm{rpm}$, Laurell WS 650 Spin Coater, Laurell Technologies Corp., North Wales, PA, USA) or by dip-coating (diluted polymer solution with $40 \%$ distilled water). Plates were immediately transferred to a pre-heated stove at $110^{\circ} \mathrm{C}$ (Memmert, model 30, Memmert GmgH, Schwabach, Germany) for 30 minutes for reticulation. The plates were then sonicated in pure ethanol for five minutes for adequate removal of any remaining physisorbed particles. Control plates underwent the same protocol with distilled water instead (spin-coating or dip-coating, heating, sonication).

\section{3) Surface characterization}

$X$-ray Photoelectron Spectroscopy (XPS): 
97 XPS analyses were performed using an Omicron Argus X-ray photoelectron spectrometer. The monochromated $\mathrm{AlK}_{\alpha}$ radiation source $(h v=1486.6 \mathrm{eV})$ had a $300 \mathrm{~W}$ electron beam power. The emission of photoelectrons from the sample was analyzed at a takeoff angle of $90^{\circ}$ under ultra-high vacuum conditions ( $\leq 10^{-10}$ Torr). Spectra were carried out with a $100 \mathrm{eV}$ pass energy for the survey scan and $20 \mathrm{eV}$ pass energy for the $\mathrm{C} 1 \mathrm{~s}, \mathrm{O} 1 \mathrm{~s}, \mathrm{~N} 1 \mathrm{~s}, \mathrm{~S} 2 \mathrm{p}$ regions. Binding energies were calibrated against the aliphatic $\mathrm{C} 1$ s contribution binding energy at $284.8 \mathrm{eV}$ and element peak intensities were corrected by Scofield factors. The peak areas were determined after subtraction of a linear background. The spectra were fitted using Casa XPS v.2.3.15 software (Casa Software Ltd., U.K.) and applying a Gaussian/Lorentzian ratio G/L equal to 70/30.

\section{Polarization Modulation Reflection Absorption Infra-Red Spectroscopy (PM-RAIRS):}

PM-RAIRS analyses were performed in air with the crystal placed in the external beam of a Fourier transform infrared Nicolet 5700 spectrometer (Nicolet Nexus 5700, Thermo Electron Scientific Instruments Corporation, Madison ${ }^{\circledR}$, WI, USA).; the experimental setup was described elsewhere (20). All reported spectra were recorded at $8 \mathrm{~cm}^{-1}$ resolution by coaddition of 128 scans; using a modulation of polarization enabled us to perform rapid analyses of the samples after immersion without purging the atmosphere or requiring a reference spectrum.

\section{Surface charge determination by fluorescein test:}

Surface cationic density $\left(\mathrm{NH}_{4} / \mathrm{cm}^{2}\right)$ was calculated by a fluorescein test. It is estimated that each fluorescein molecule (negatively charged) strongly binds quaternary ammonium molecules (positively charged) belonging to the polymeric chain. Treated plates were placed in a $2 \%$ fluorescein aqueous solution for five minutes. They were then rinsed and sonicated for five minutes in order to remove physisorbed fluorescein. Plates were rinsed in distilled water a second time, immersed in a test tube containing CTAB 0,1\% (aqueous solution of cetyl trimethylammonium bromide) diluted in PBS (Phosphate-Buffered Saline) (90\% CTAB/10\% PBS) and vortexed for 10 seconds. Fluorescein was then dissolved, allowing an optical density measurement using a spectrophotometer at $501 \mathrm{~nm}$ wavelength (CamSpec M550, Spectronic Camspec Ltd, Leeds, UK). Measurements were repeated three times.

Surface cationic density was estimated according to the following formula: 

A: fluorescein optical density at $501 \mathrm{~nm}$
$\mathrm{V}$ : volume
NA: Avogadro number $\left(6.022140857 \times 10^{23} \mathrm{~mol}^{-1}\right)$
$\varepsilon$ : fluorescein molar absorptivity or molar extinction coefficient $\left(\mathrm{L} \times m o l^{-1} \mathrm{x} \mathrm{cm}^{-1}\right)$.

The impact of coating thickness on fluorescein tests was also assessed. Spin-coating was either performed in a single round $(125 \mu \mathrm{L}$ in 40 seconds) or six rounds (six $125 \mu \mathrm{L}$ drops, 40 seconds each). Plates were either labelled SLSC (single-layer spin-coating) or MLSC (multi-layer spincoating).

\section{Polymer leaching:}

Eight plates spin-coated with Q-PVP-4 days, either SLSC or MLSC, underwent a 1-week leaching test at $37^{\circ} \mathrm{C}$ and were immersed in two different mediums: SLSC plates in distilled water ( $\mathrm{n}=2)$, SLSC in rabbit serum (Sigma-Aldrich, Saint-Louis, MO, USA) (n=2), MLSC plates in distilled water $(n=2)$, MLSC plates in rabbit serum $(n=2)$. A fluorescein test was performed to determine the remaining surface charge density percentage (RSCD) after one week. Measurements were repeated three times.

\section{Atomic force microscopy (AFM) surface analysis:}

Grafted and control titanium plate imaging was performed using a commercial atomic force microscope (Bruker Nano Inc.-Nano Surfaces Division, Santa Barbara, CA, USA) equipped with a $\mathrm{J}$ scanner $(150 \times 150 \times 5 \mu \mathrm{m})$. Images were analyzed in "QNM ${ }^{\circledR}$ " mode (Quantitative Nanomechanical Property Mapping) in air or "intermittent-contact" mode in a quartz measure cell. Sharps were made of silicon nitride $\left(\mathrm{Si}_{3} \mathrm{~N}_{4}\right)$ and had a theoretical stiffness constant of $0.05 \mathrm{~N} . \mathrm{m}^{-1}$ and a curve ray of $20 \mathrm{~nm}$. Observations were done at a constant speed of $1 \mathrm{~Hz}, 512$ lines of 512 pixels each, being recorded for each image. Data were analyzed using Nanoscope Analysis software (Bruker, Santa Barbara, CA, USA). The displayed images are 3D reconstructions of height and DMT modulus images.

Scanning Electron Microscopy with Field Emission Gun (SEM-FEG) surface analysis: 
SEM images were recorded with a Hitachi SU-70 field emission gun scanning electron microscope. The samples were fixed on an alumina SEM support with a carbon adhesive tape and were observed without metallization. An in-lens secondary electron detector ( $\left.\mathrm{SE}_{\mathrm{Upper}}\right)$ was used to characterize our samples. The accelerating voltage was $1 \mathrm{kV}$, and the working distance was around $5 \mathrm{~mm}$. At least five different locations were analysed on each surface, arising to the observation of a minimum of 100 single cells.

\section{Irradiation test:}

Dip-coated titanium plates were sterilized by gamma irradiation from a ${ }^{6}{ }^{0}$ Co source with a total delivered dose of 27kGy (minimum threshold 25kGy, ISO 11137-2: 2013) (21). The irradiation was performed at $0^{\circ} \mathrm{C}$ for 4 hours (BBF Sterilisationsservice $\mathrm{GmbH}$, Kernen, Germany) to prevent denaturation of the polymer during the sterilization process. Infra-red spectra were compared before and after irradiation to verify the integrity of the polymer at the surface.

\section{4) Biocompatibility Assessment:}

MTT Viability Test:

A murine osteoblast precursor cell line (MC3T3-E1) was cultured in MEM- $\alpha$ (Gibco Invitrogen, France) enriched with 10\% FBS (fetal bovine serum), $2 \mathrm{mM}$ glutamine, $100 \mathrm{U} / \mathrm{mL}$ penicillin and $100 \mu \mathrm{g} / \mathrm{mL}$ streptomycin. Murine fibroblasts (L929) were also cultured separately in DMEM (Dulbecco's Mod Eagle Medium) supplemented with 10\% FBS, 2mM glutamine, $100 \mathrm{U} / \mathrm{mL}$ penicillin and $100 \mu \mathrm{g} / \mathrm{mL}$ streptomycin.

$5 \times 10^{5}$ cells of each cell line were seeded on each titanium plate in their respective medium $(1 \mathrm{~mL})$ in $24-w e l l$ plates. Five triplicate conditions were tested (control, Q-PVP-iodo, Q-PVP36h, Q-PVP-2days, Q-PVP-4days, Q-PVP-PEG) in order to further elucidate the consequences of the introduction of specific chains in the polymer on cell viability. All tested surfaces were spin-coated. In both cases, following incubation at $37^{\circ} \mathrm{C}$ in humid atmosphere and $5 \% \mathrm{CO}_{2}$, a trypsin EDTA treatment was applied in order to retrieve adherent cells. The protocol was repeated three times for each cell line. Finally, an MTT assay comparing optical densities at 
$550 \mathrm{~nm}$ was then performed in order to measure cell viability at $72 \mathrm{~h}$ (Wallac 1420 Victor2 TM microplate reader, Perkin Elmer, Waltham, MA, USA). 70\% cell viability was considered to be the critical threshold. Measurements were averaged on each triplicate and presented with mean \pm SEM (standard error of the mean).

SEM-FEG cell adhesion and morphological analysis:

L929 and MC3T3 cells were cultured on titanium plates spin-coated and grafted with Q-PVPiodo, Q-PVP-36h, Q-PVP-2days, Q-PVP-4days until 72h under the conditions described previously. All titanium plates underwent the following fixation protocol: plates were rinsed three times with PBS 5\% and fixed in 2,5\% glutaraldehyde (2 hours). The fixative was then drained off and plates were immersed in ethanol at room temperature as follows: $25 \% \mathrm{EtOH}$ (5 minutes), $50 \% \mathrm{EtOH}$ (5 minutes), $75 \% \mathrm{EtOH}$ (5 minutes), 100\% EtOH (5 min) and finally dried under a fume hood. Cell adhesion behavior was assessed by SEM-FEG.

\section{5) Antibacterial activity:}

An ST 2012-238 MRSA strain (Lyon, France) isolated from a patient with a PJI (prosthetic joint infection) was cultured in Brain Heart Infusion (BHI) at $37^{\circ} \mathrm{C}$ overnight. According to a modification of the 22196:2011 ISO norm, a $10^{7} \mathrm{CFU} / \mathrm{mL}$ bacterial suspension of $20 \mu \mathrm{L}$ in rich medium (BHI) was simultaneously deposited and applied with cover slips on titanium plates (control versus grafted with Q-PVP-iodo, Q-PVP-36h, Q-PVP-2 days, Q-PVP4 days, Q-PVP-PEG using spin coating or dip coating) inside 24-well culture plates for triplicate. Culture plates were then transferred to a stove at $37^{\circ} \mathrm{C}$. Cultures were sequentially stopped after $1 \mathrm{~h}$ (bacterial "killing" at $37^{\circ} \mathrm{C}$ ) and $24 \mathrm{~h}$ (growth inhibition at $37^{\circ} \mathrm{C}$ ), diluted in $0.9 \%$ saline and vortexed for detachment of live bacteria and bacterial counting.

\section{6) Antibiofilm activity:}

Q-PVP-4days dip-coated titanium plates were placed into 24-well culture plates. A $10^{6}$ $\mathrm{CFU} / \mathrm{mL}$ bacterial suspension in $1 \mathrm{~mL}$ of $\mathrm{BHI}$ (prepared as described above) was used to fill wells containing titanium plates. Culture plates were then transferred to a stove for culture at $37^{\circ} \mathrm{C}$. Cultures were then stopped sequentially each time for two control and two grafted titanium plates after respectively $6 \mathrm{~h}, 12 \mathrm{~h}, 24 \mathrm{~h}, 72 \mathrm{~h}$, and 7 days (medium was removed and 
replaced with sterile BHI every 24h). An in vitro biofilm of gradual maturity was therefore created on dip-coated titanium plates and controls. In order to determine the influence of BHI on plate surface morphology, two other control titanium plates were prepared: one was immersed in sterile BHI throughout the experiment and underwent fixation while the other was activated by piranha treatment and underwent fixation afterwards. All titanium plates underwent the fixation protocol described above. SEM-FEG imaging on treated and control titanium plates covered with $6 \mathrm{~h}$ to 7 day biofilm were obtained.

\section{7) Killing Activity}

A killing test was performed on Q-PVP-4days plates (controls versus treated) at $20^{\circ} \mathrm{C}$ following a three-hour contact with a $10^{7} \mathrm{CFU} / \mathrm{mL}$ MRSA inoculum. For the latter, AFM imaging was performed.

\section{8) Statistical analysis}

For comparisons of two means, a Student t-test was used. All statistical analyses were performed with Prism 5 (Graphpad software). P-values below 0.05 were considered significant and $\mathrm{p}$-values were represented as follows: $*=\mathrm{P}<0.05$, $* *=\mathrm{P}<0.01$.

\section{RESULTS:}

\section{1) Surface characterization}

X-Ray Photoemission Spectroscopy (XPS)

257 XPS experiments were performed on both dip and spin-coated quaternized surfaces (Q-PVP258 4days) compared to bare surfaces before any functionalization. First, one can notice on the 259 control surface that most of layer of the sample is composed of $\mathrm{TiO} 2$ oxidized titanium, with 260 the main contribution of the Ti2p3/2 signal being centered at $459.0 \mathrm{eV}$ and only a very small 261 contribution (less than $3 \%$ ) of metallic titanium visible at $454.1 \mathrm{eV}$.

262 The second conclusion that can be drawn from these data is the equivalent thickness of the 263 functionalized surface. In fact, one can estimate that thickness by looking at the decrease of the $264 \mathrm{Ti}$ signal after functionalization, taking into account that the mean free path $(\lambda)$ of $\mathrm{TiO}_{2}$ 
electrons onto organic films is around $\lambda=2.85 \mathrm{~nm}$. In the case of the dip coated method, the XPS Ti2p signal is completely extinguished suggesting an equivalent thickness of the Q-PVP4 days film superior to $3 \lambda$, i.e. superior to $8.5 \mathrm{~nm}$, while for the spin coating method, the $\mathrm{TiO}_{2}$ signal is still faintly visible, suggesting an equivalent thickness of $8 \mathrm{~nm}$ for the Q-PVP-4 days 269 films.

270 Finally, chemical composition details can be obtained when looking at the different atomic 271 percentages of the different films as compared to non-functionalized control, Table 1, showing 272 that similar amount of Q-PVP-4days is grafted on the surface, regardless of the deposition 273 method.

275 Table 1: Atomic percentage obtained from XPS data for spin and dip coated films as compared 276 to non functionalized surface.

\begin{tabular}{|l|l|l|l|l|}
\hline Atomic \% & Ti2p & O1s & C1s & N1s \\
\hline TiO2 control surface & 17.5 & 41.4 & 40.2 & 0.9 \\
\hline Spin-coated surface & 0.3 & 6.5 & 87.6 & 5.6 \\
\hline Dip-coated surface & ND & 4.3 & 89.8 & 5.9 \\
\hline
\end{tabular}

$277 \mathrm{ND}=$ non detectable; \% are obtained as mean of two measurements, the standard deviation of 278 the measure is around $0.2 \%$.

\section{Polarization Modulation Infra-Red Reflection Absorption Spectroscopy (PM-IRRAS):}

Polyvinylpyridine quaternization was modulated depending on reaction time (Q-PVPiodo in 12 hours, Q-PVP-36h, Q-PVP-2days, Q-PVP-4days) leading to grafted polymers with increasing $\frac{N^{+}}{N}$ ratios along with increased reaction time. The $\frac{N^{+}}{N}$ ratio was determined through PM-IRRAS spectra using the area ratio between the stretching mode of the $\mathrm{C}-\mathrm{N}^{+}$band $(1640$ $\left.\mathrm{cm}^{-1}\right)$ and $\mathrm{C}-\mathrm{N}$ band $\left(1600 \mathrm{~cm}^{-1}\right)$ by looking at the very specific IR marker present at $1640 \mathrm{~cm}^{-}$ ${ }^{1}$ assigned to the protonated amino groups. One can notice that this contribution is increasing as a function of reaction time (Figure 2). 


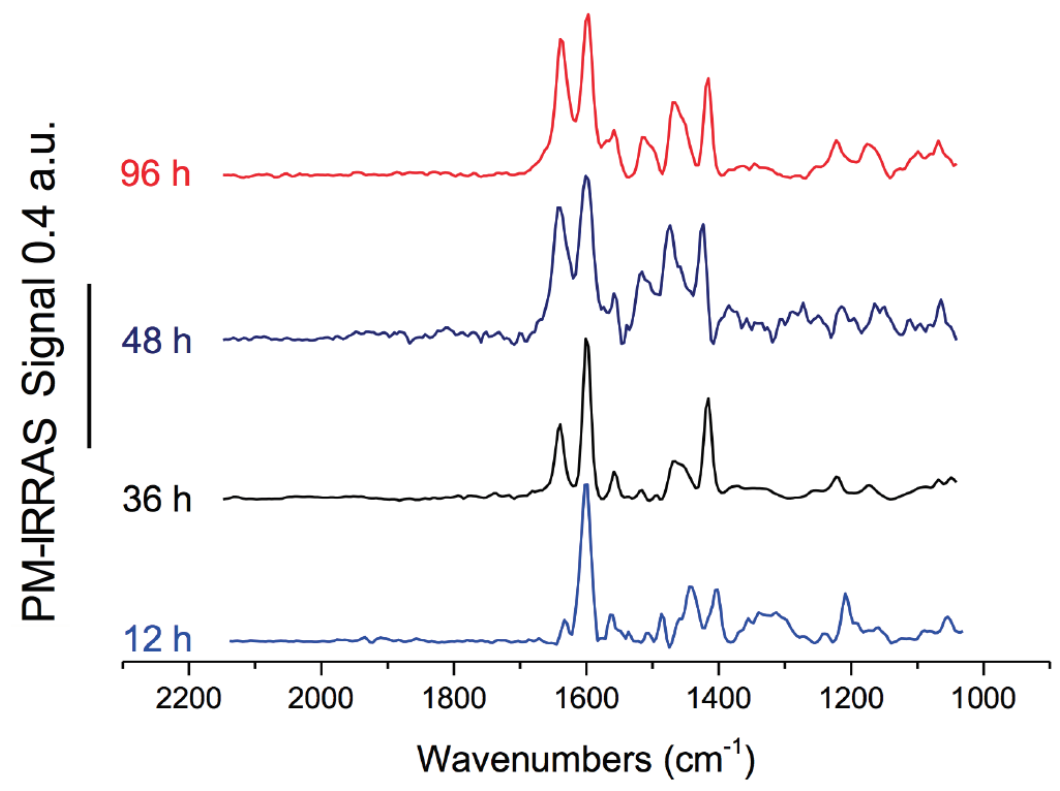

Figure 2. PM-RAIRS spectra following deposition and copolymer grafting on titanium: quaternization increased with reaction time (12 h to $96 \mathrm{~h}$ ).

The $\frac{N^{+}}{N}$ ratio are presented on Table 2 for each reaction, and one can see that a stable regime is achieved after 48 hours of reaction time, with no more possible quaternization even with twice longer reaction time, eg. 96 hours.

313 Table 2: \% of quaternization of the copolymer as a function of reaction time.

\begin{tabular}{|c|c|c|c|c|}
\hline Reaction time (hours) & $\mathbf{1 2}$ & $\mathbf{3 6}$ & $\mathbf{4 8}$ & $\mathbf{9 6}$ \\
\hline Ratio $: \frac{\boldsymbol{N}^{+}}{\boldsymbol{N}}(\boldsymbol{\%})$ & $12.1 \pm 0.5$ & $31.3 \pm 0.7$ & $44.6 \pm 1.2$ & $45.9 \pm 2$ \\
\hline
\end{tabular}

315 Scanning Electron Microscopy with Field Emission Gun (SEM-FEG):

317 Grafted surfaces appeared smoother than control plates despite identical polishing. 318 Imperfections in polishing were more easily visible on control plates and grafted plates after 319 BHI sedimentation and fixation. Despite this, all surfaces were relatively homogeneous. Neither 320 the BHI sedimentation nor the fixation protocol seemed to cause further chemical abrasion of 321 titanium surfaces (Figure 3). 

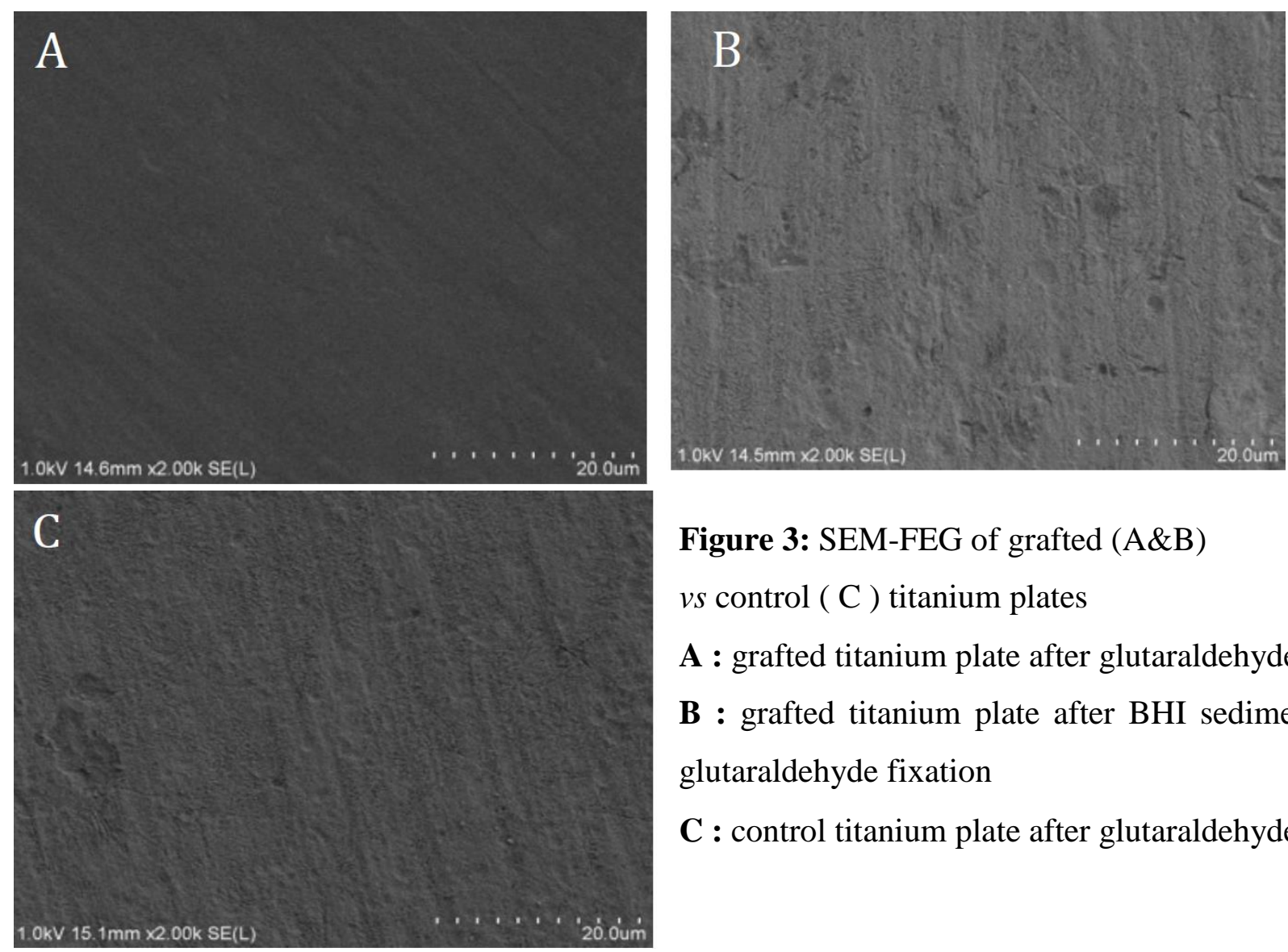

Figure 3: SEM-FEG of grafted $(A \& B)$

$v s$ control ( C ) titanium plates

A : grafted titanium plate after glutaraldehyde fixation

B : grafted titanium plate after BHI sedimentation and glutaraldehyde fixation

C : control titanium plate after glutaraldehyde fixation

Atomic Force Microscopy (AFM):

Grafted and control surfaces presented a near identical roughness (controls: $23.0 \mathrm{~nm}$ vs grafted:

$22.6 \mathrm{~nm})$. Grafted surfaces were chemically homogeneous.
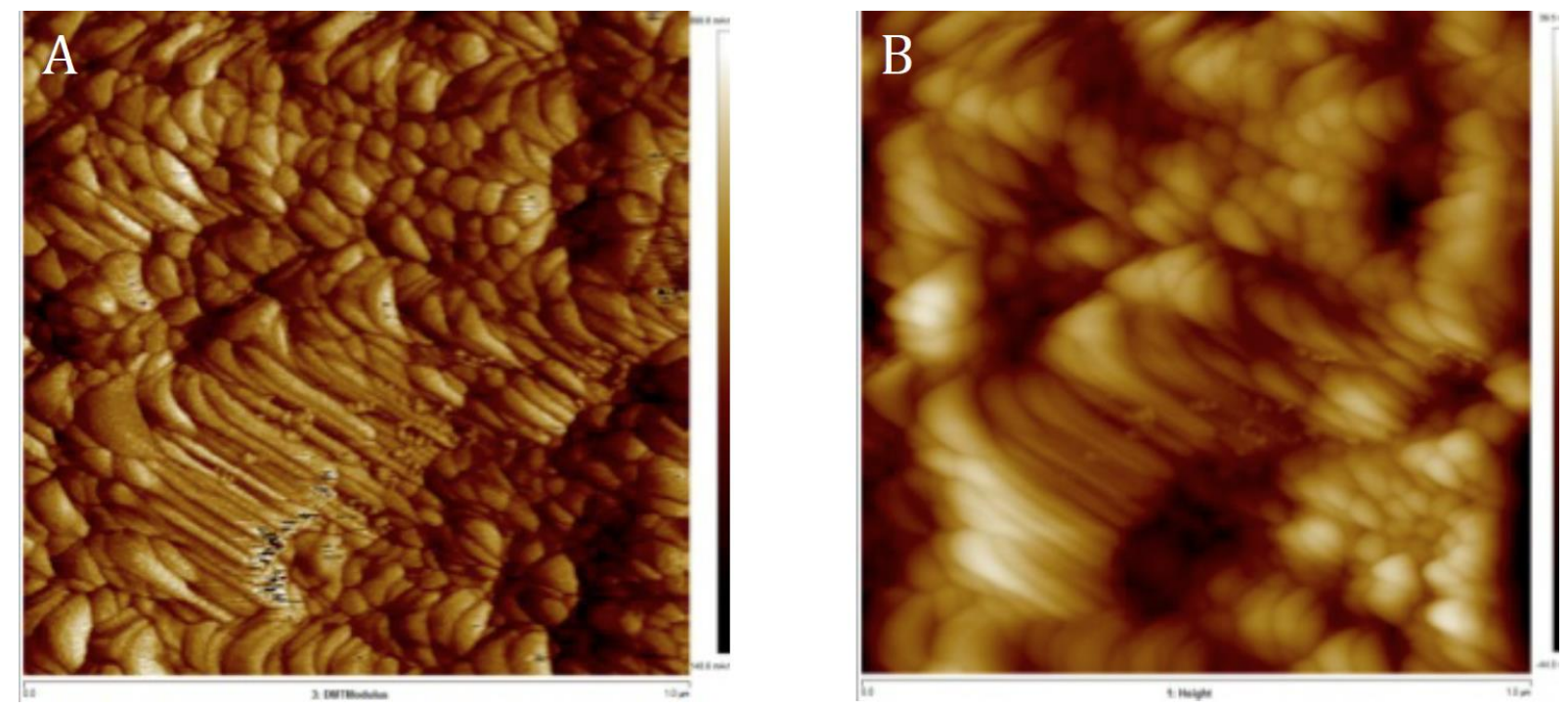

Figure 4: AFM imaging of a control titanium plate ( $1 \mu \mathrm{m}$ scale) 
A: DMT Modulus: chemically homogeneous sample (pure titanium).

337

338

6

7

8

9

10

11

12

13

14

15

16

17

18

19

20

21

22

23

24

25

26

27
B: Height mode : sample roughness after polishing: $23 \mathrm{~nm}$.
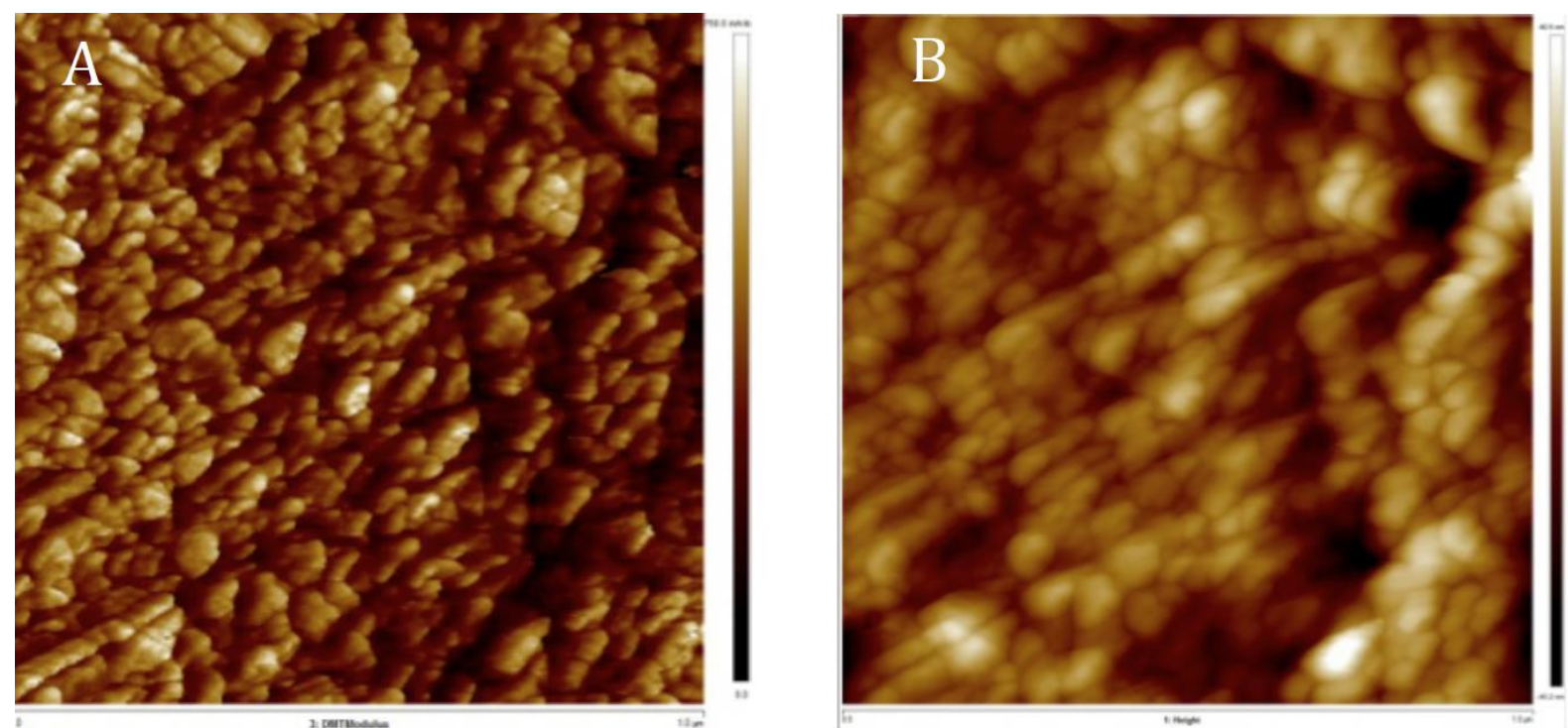

Figure 5: AFM imaging of grated plates spin-coated with Q-PVP-4days ( $1 \mu \mathrm{m}$ scale).

A: DMT (Derjaguin-Muller-Toporov) Modulus: grafted polymer appears chemically homogeneous on the titanium surface

B: Height mode: grafted polymer layer, roughness : 22,6nm

2) Surface charge determination by fluorescein test:

SLSC Q-PVP-36h showed systematically higher absorbance than plates that were spin-coated in a single round with Q-PVP-4days $\left(0.296 \pm 0.034\right.$ or $2.31 \times 10^{17}$ charges $/ \mathrm{cm}^{2}, \mathrm{n}=6$ vs $0.133 \pm$ 0.026 or $1.04 \times 10^{16}$ charges $/ \mathrm{cm}^{2}, \mathrm{n}=6$ ). SLSC Q-PVP-2days plates averaged $0.130 \pm 0.040$ $(n=3)$ with an estimated surface charge density of $1.02 \times 10^{17}$ charges $/ \mathrm{cm}^{2}$.

\section{3) Polymer Leaching}

MLSC plates showed a tendency towards lower leaching than single SLSC plates in rabbit serum though it was more significant in distilled water (respectively $47.55 \pm 22.13 \%$ vs 68.95 $\pm 13.36 \%$ and $72.30 \pm 1.13 \%$ vs $88.65 \pm 3.61 \%$ ). Furthermore, leaching in rabbit serum was systematically lower than in distilled water while assessing similar coating thicknesses.

Fluorescein test measurements with leaching and RSCD calculations are reported in Table 3. 
1
Table 3. Surface charge determinations on titanium plates grafted with Q-PVP-4 days before 363 and after a 7-day immersion in either rabbit serum or distilled water.

\begin{tabular}{rcccccccc}
\hline \multicolumn{3}{c}{ RABBIT SERUM } & & & \multicolumn{3}{c}{ DISTILLED WATER } \\
\hline & $\mathbf{t}=\mathbf{0}$ & $\mathbf{t}=\mathbf{7}$ days & Leaching $\%$ & RSCD & $\mathbf{t}=\mathbf{0}$ & $\mathbf{t = 7}$ days & Leaching \% & RSCD \\
\hline SLSC1 & $0.125 \pm 0.004$ & $0.027 \pm 0.005$ & 78,40 & $2,11 \mathrm{E}+15$ & & & & \\
SLSC2 & $0.101 \pm 0.013$ & $0.041 \pm 0.008$ & 59,50 & $3,21 \mathrm{E}+15$ & & & & \\
SLSC3 & & & & & $0.137 \pm 0.014$ & $0.012 \pm 0.005$ & 91,2 & $9,382 \mathrm{E}+14$ \\
SLSC4 & & & & $0.108 \pm 0.07$ & $0.015 \pm 0.003$ & 86,1 & $1,173 \mathrm{E}+15$ \\
MLSC 1 & $0.494 \pm 0.023$ & $0.182 \pm 0.006$ & 63,20 & $1,42 \mathrm{E}+16$ & & & & \\
MLSC 2 & $0.457 \pm 0.009$ & $0.311 \pm 0.005$ & 31,90 & $2,43 \mathrm{E}+16$ & & & & \\
MLSC 3 & & & & & $0.295 \pm 0.008$ & $0.084 \pm 0.011$ & 71,5 & $6,567 \mathrm{E}+15$ \\
MLSC 4 & & & & & $0.360 \pm 0.029$ & $0.097 \pm 0.018$ & 73,1 & $7,584 \mathrm{E}+15$ \\
\hline
\end{tabular}

\section{4) Biocompatibility assessment (MTT-assay)}

367 Mean MC3T3 absorbance on control titanium plates was $0.42 \pm 0.02$, arbitrarily considered $368100 \%$ viability. MC3T3 cell viability decreased on plates displaying higher surface cationic 369 densities compared with controls (from Q-PVP-iodo (118\% $\pm 5.4 \%$ survival) to Q-PVP-4 days $370(73 \% \pm 5.1 \%)$. If the initial reaction did not include a bromobutane chain and lasted only 12 371 hours (Q-PVP-iodo), cells deposited on grafted titanium surfaces persistently showed higher 372 cell survival at $72 \mathrm{~h}$ than cells on control titanium plates $(118 \% \pm 5.4 \%)$. Of all tested samples, 

386

M.T.T MC3T3 $72 \mathrm{~h}$

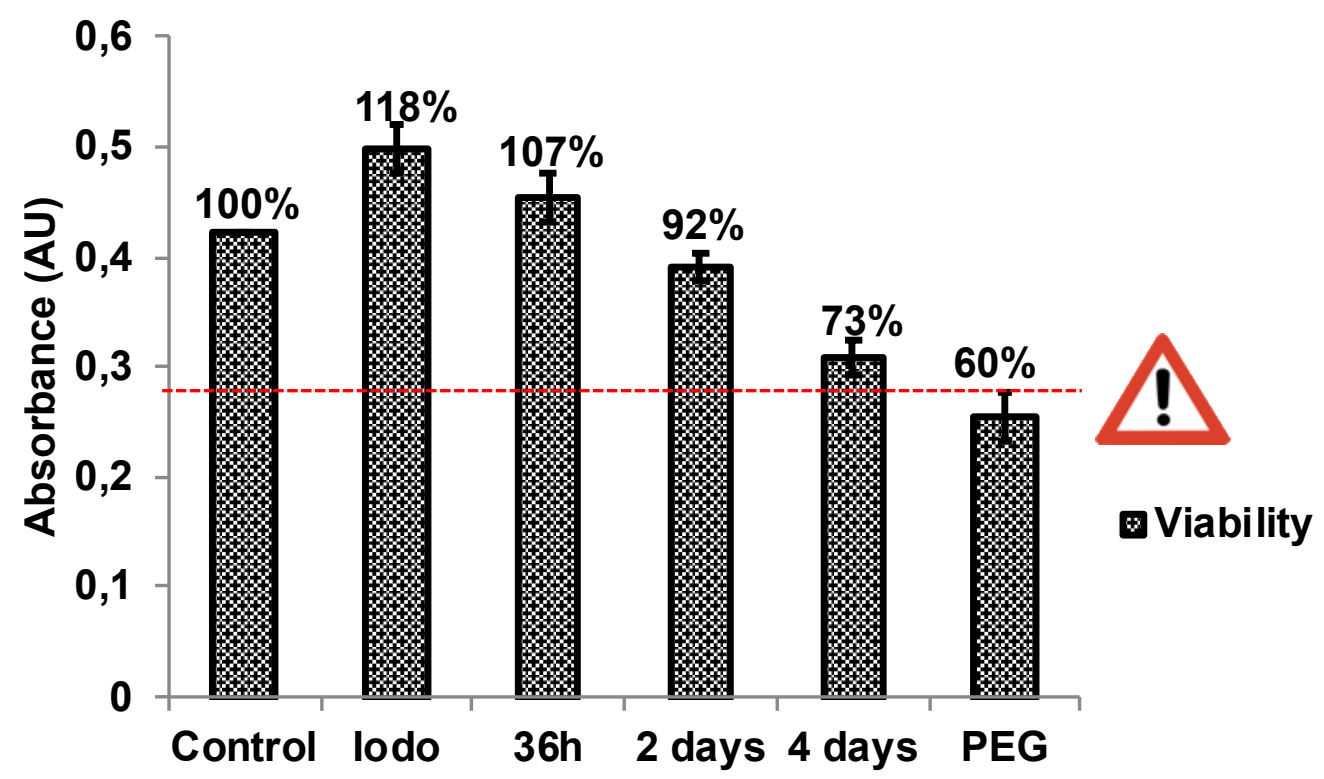

Figure 6. MTT-assay: M3T3 cell survival at 72h on surfaces of various cationic densities Controls: n=9 ; Q-PVP-iodo: n=9 ; Q-PVP-36h: n=9 ; Q-PVP-2 days: $\mathrm{n}=8$; Q-PVP-4 days: 7 ; Q-PVP-PEG: $\mathrm{n}=3$. All data are represented as mean \pm standard error. All treated plates showed statistically significant differences in absorbance values compared with control $(\mathrm{P}<0.05)$ except for Q-PVP-36h. The red-dotted line represents the minimum acceptable viability (70\%).

Mean L929 absorbance on control titanium plates was $0.27 \pm 0.002$, arbitrarily considered $100 \%$ viability. L929 cell viability gradually decreased on plates displaying higher cationic 387 surface densities, from Q-PVP-iodo $(96.3 \pm 2.2 \%)$ survival to Q-PVP-4 days $(87 \% \pm 1.6 \%)$. 388 Q-PVP-iodo did not increase L929 survival at 72h.

389 For each given surface cationic density, L929 cells demonstrated better survival compared with 390 MC3T3 cells at 72h 


\section{M.T.T L929 72h}

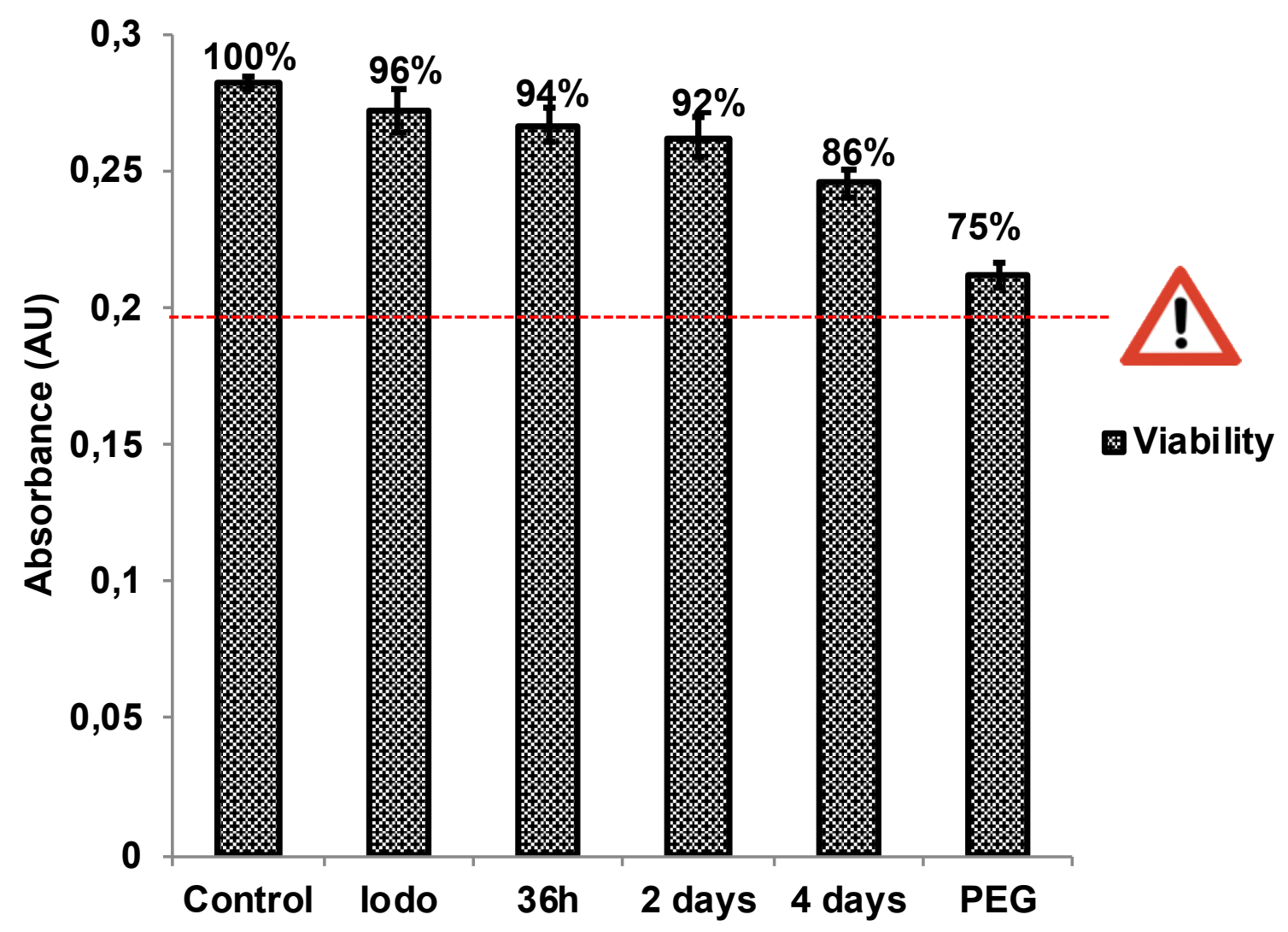

Figure 7. MTT assay: L929 cell survival after $72 \mathrm{~h}$ on surfaces of various surface charge densities. Controls: n=6 ; Q-PVP-iodo: n=6 ; Q-PVP-36h: n=6 ; Q-PVP-2 days: n=6 ; Q-PVP4 days: 3 ; Q-PVP-PEG: $\mathrm{n}=3$. All data are represented as mean \pm standard error. All treated plates showed statistically significant differences in absorbance values compared with control $(\mathrm{P}<0.05)$ except for Q-PVP-iodo. The red-dotted line represents the minimum acceptable viability $(70 \%)$.

\section{5) Biocompatibility assessment (SEM-FEG):}

Qualitative morphological assessment showed that L929 cell behavior differed in terms of adhesion, morphology and shape on depending on surface charge density. Surfaces of increased charge density decreased cell adhesion and shape. Indeed, a gradual transition in the shape of cells was observed between Q-PVP-4 days, the highest density polymer (cells mostly round, few spindle cells, few pseudopods) and Q-PVP-iodo, the lowest density polymer (mostly spindle cells, numerous pseudopods) (Figure 8). Surfaces were ranked in terms of cell-adhesion promotion: Q-PVP-iodo > Control > Q-PVP-36h > Q-PVP-2 days > Q-PVP-4 days. Plates 
9414

grafted with Q-PVP-PEG markedly reduced cell adhesion and spreading as most cells were round with few pseudopods. Cell populations on these plates stood out compared with all other polymers as the least viable.

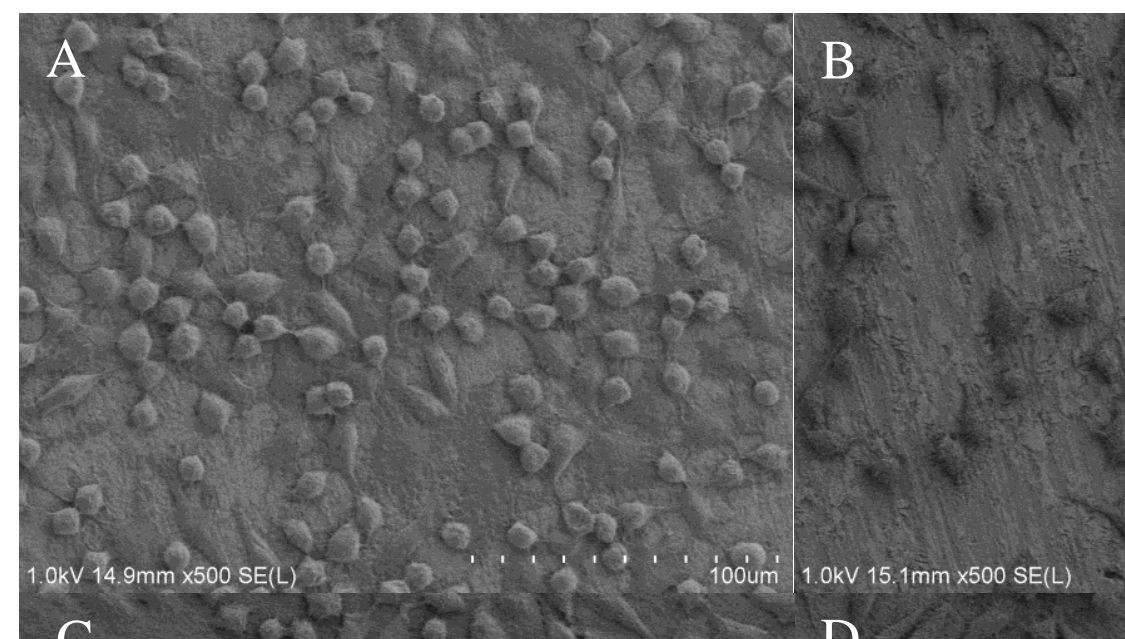

'ún'

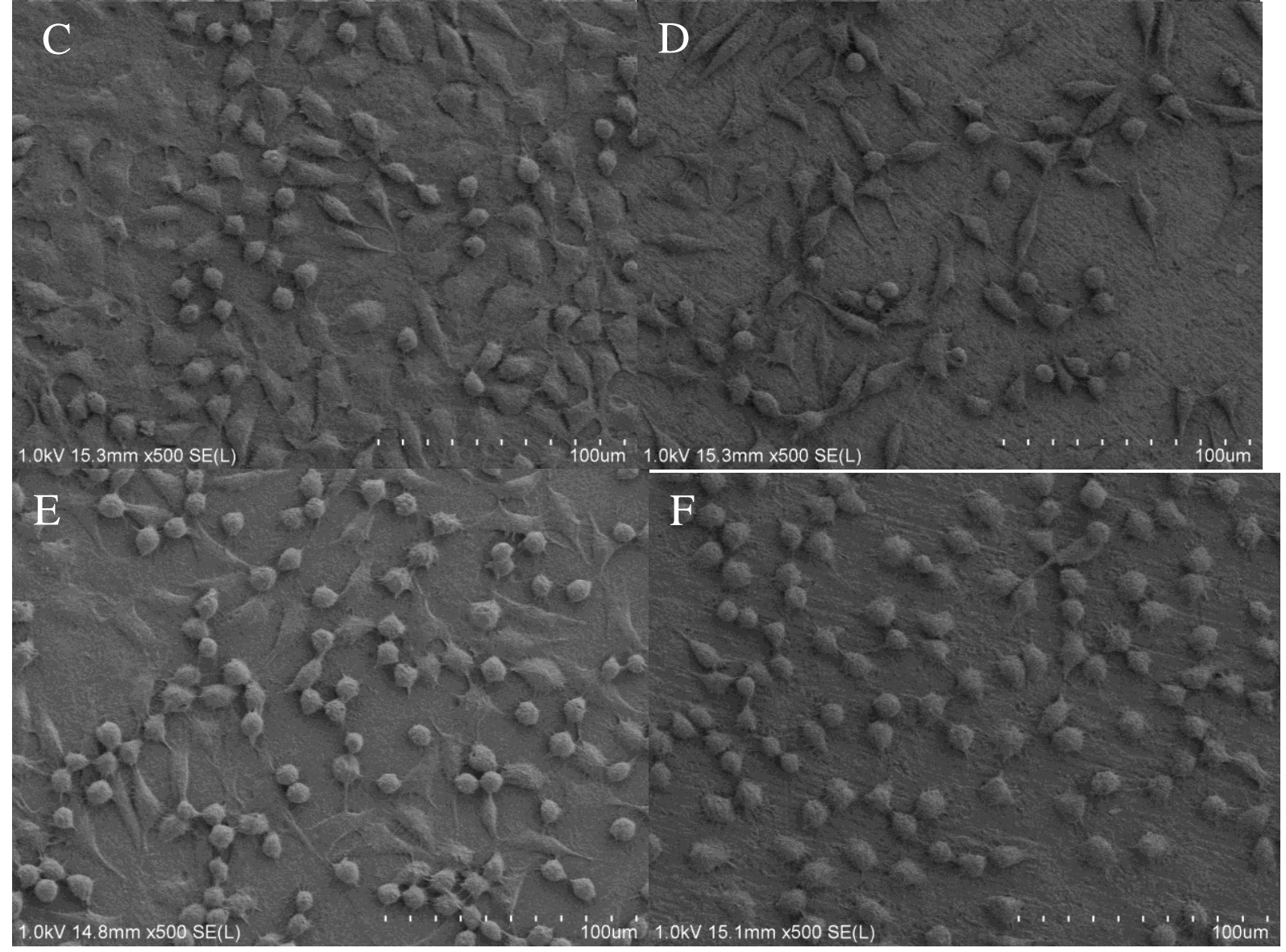

Figure 8: SEM-FEG imaging displaying gradual adherence decrease (fewer pseudopods, rounder cells) and density decrease of L929 cells on surfaces of increasing cationic densities 
421 and especially Q-PVP-PEG. A: Control; B: Q-PVP-36h; C: Q-PVP-2 days, D: Q-PVP-iodo, E:

1

3

5

742

8

9

10
422 Q-PVP-4 days, F: Q-PVP-PEG

423 Qualitative morphological assessment showed that MC3T3 cell behavior also differed in terms 424 of adhesion, morphology and shape on depending on surface charge density. Surfaces of 25 increased charge density decreased cell adhesion and shape. Indeed, a gradual transition in the shape of cells was observed between Q-PVP-4 days (scarce cells observed) and Q-PVP-iodo or controls (large, well defined, flat and spread cells). Q-PVP-PEG coated surfaces displayed abnormally shaped cells, round, poorly spread and obviously lacking adherence compared with controls. Again, Q-PVP-PEG surfaces stood out from the rest of samples as the least suitable for cell viability.




Figure 9: SEM-FEG imaging displaying gradual adherence decrease of MC3T3 cells on surfaces of increases cationic densities and Q-PVP-PEG. A: Control; B: Q-PVP-iodo; C: Q-PVP-36h, D: Q-PVP2days, E: Q-PVP-4days, F: Q-PVP-PEG

\section{6) Bactericidal activity}

In vitro assays on MRSA demonstrated a fast (within one hour) and highly efficient killing activity on surfaces grafted with Q-PVP-4 days, especially on dip-coated titanium (complete sterilization, Figure 10). Under proliferating conditions $\left(37^{\circ} \mathrm{C}\right.$ in a rich medium, BHI), the observed bacterial growth inhibition was more modest, though significant (Figure 11).

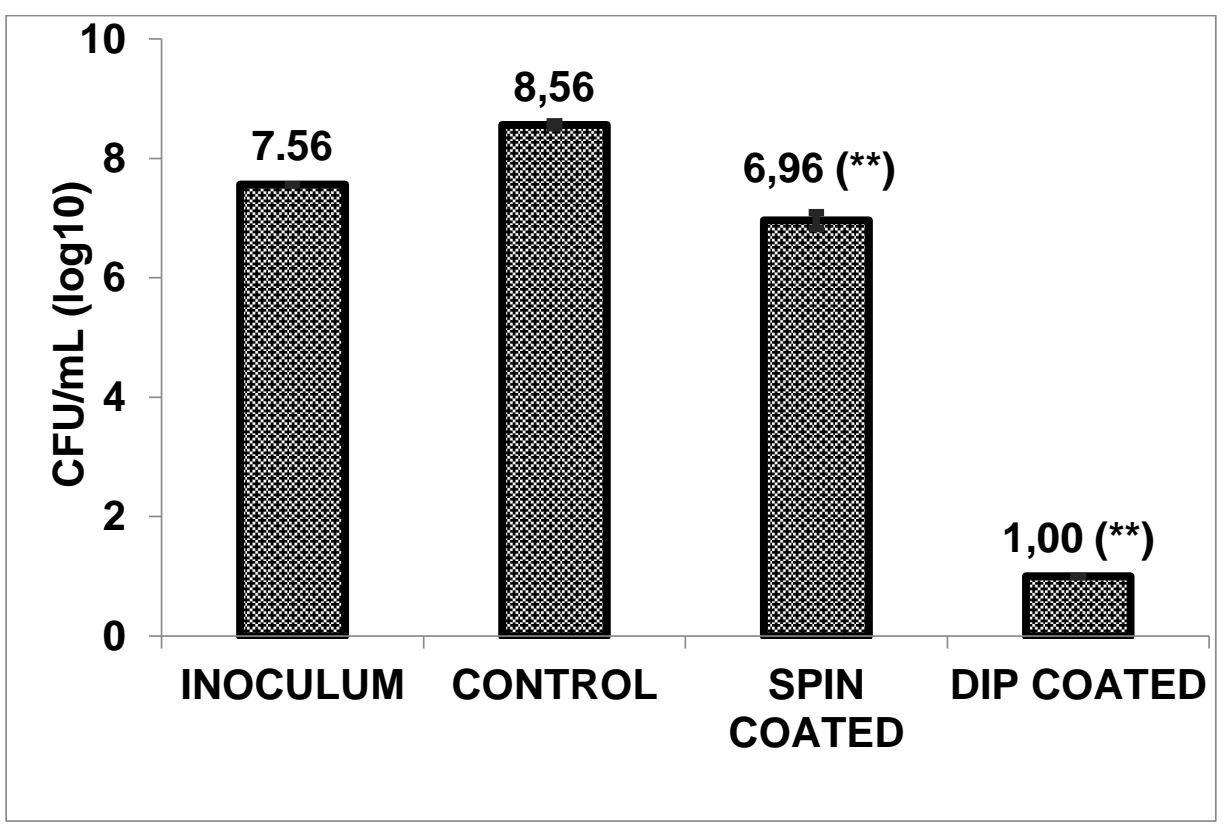

Figure 10: In vitro killing ( 1 hour) in rich medium (BHI) at $37^{\circ} \mathrm{C}$. Inoculum: $n=1$ represents the bacterial count $(\mathrm{CFU} / \mathrm{mL})$ of the bacterial suspension initially deposited on titanium substrates ; Control: $n=9$; Spin-coated: $n=9$; Dip-coated: $n=9$; All data are represented as mean \pm standard error. All treated plates showed statistically significant differences in bacteriological count values compared with control $(\mathrm{P}<0.01)$. 


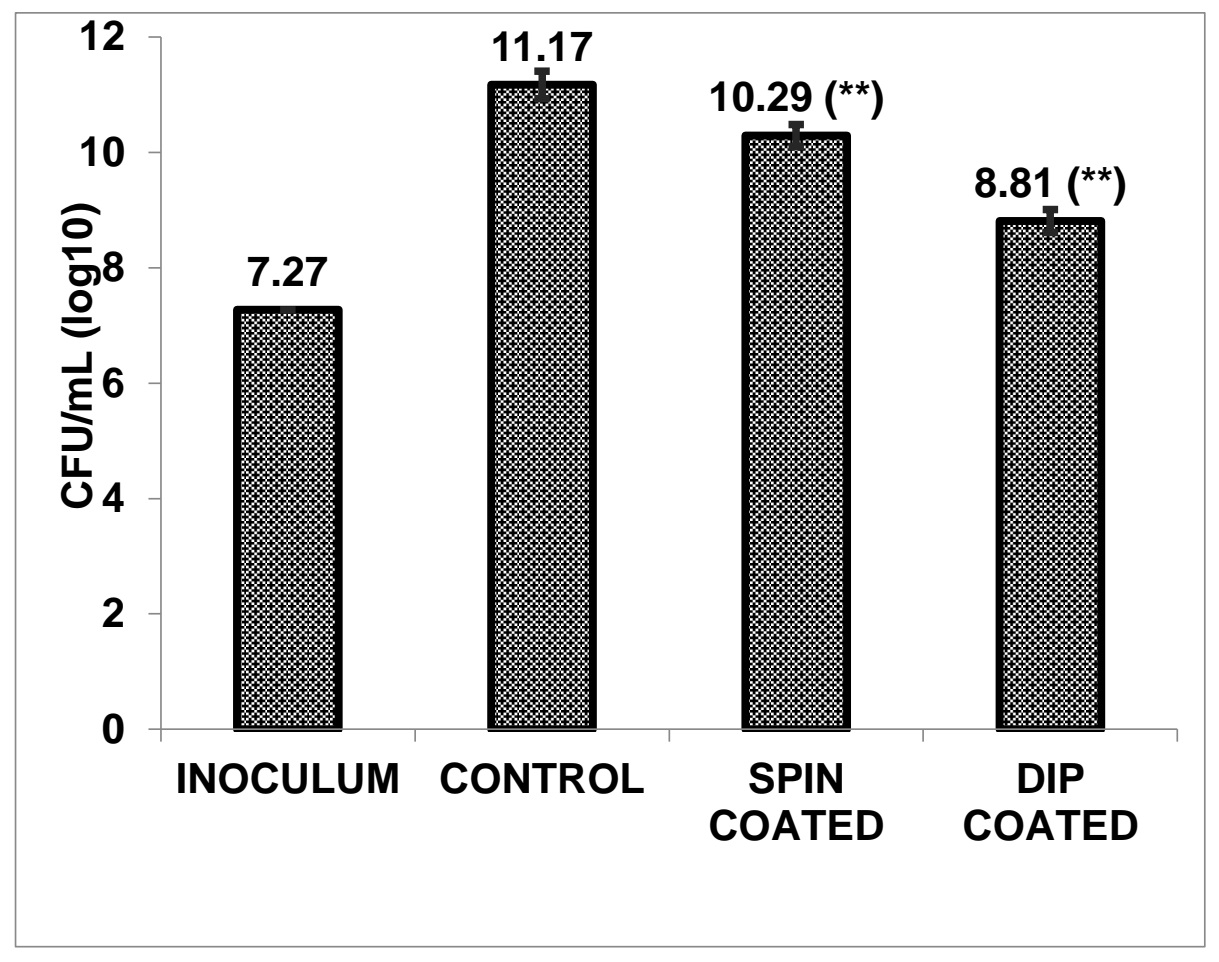

Figure 11: In vitro growth inhibition (24 hours) in rich medium (BHI) at $37^{\circ} \mathrm{C}$. Inoculum: $n=1$; Control: $n=9$; Spin-coated: $n=9$; Dip-coated: $n=9$; All data are represented as mean \pm standard error. All treated plates showed statistically significant differences in bacteriological count values compared with control $(\mathrm{P}<0.01)$.

\section{7) Antibiofilm activity}

SEM-FEG imaging revealed a rapid-onset bacterial adherence reduction on a young biofilm (6 hours) on dip-coated titanium plates (Q-PVP-4 days). The effect was prolonged despite systematic medium replacement and enriching with BHI every 24 hours. At seven days, the observed biofilm appeared multi-layered and richer on control plates compared with grafted plates. On grafted plates, biofilm was scattered across the surface and made the underlying titanium support still visible on numerous areas (Figure 12). 
1

2

3 4

These findings were also verified using 3D AFM. Bacterial perforation and volume loss was observed on killed bacteria after a 3 hours contact with Q-PVP-4 days dip-coated titanium compared with control.

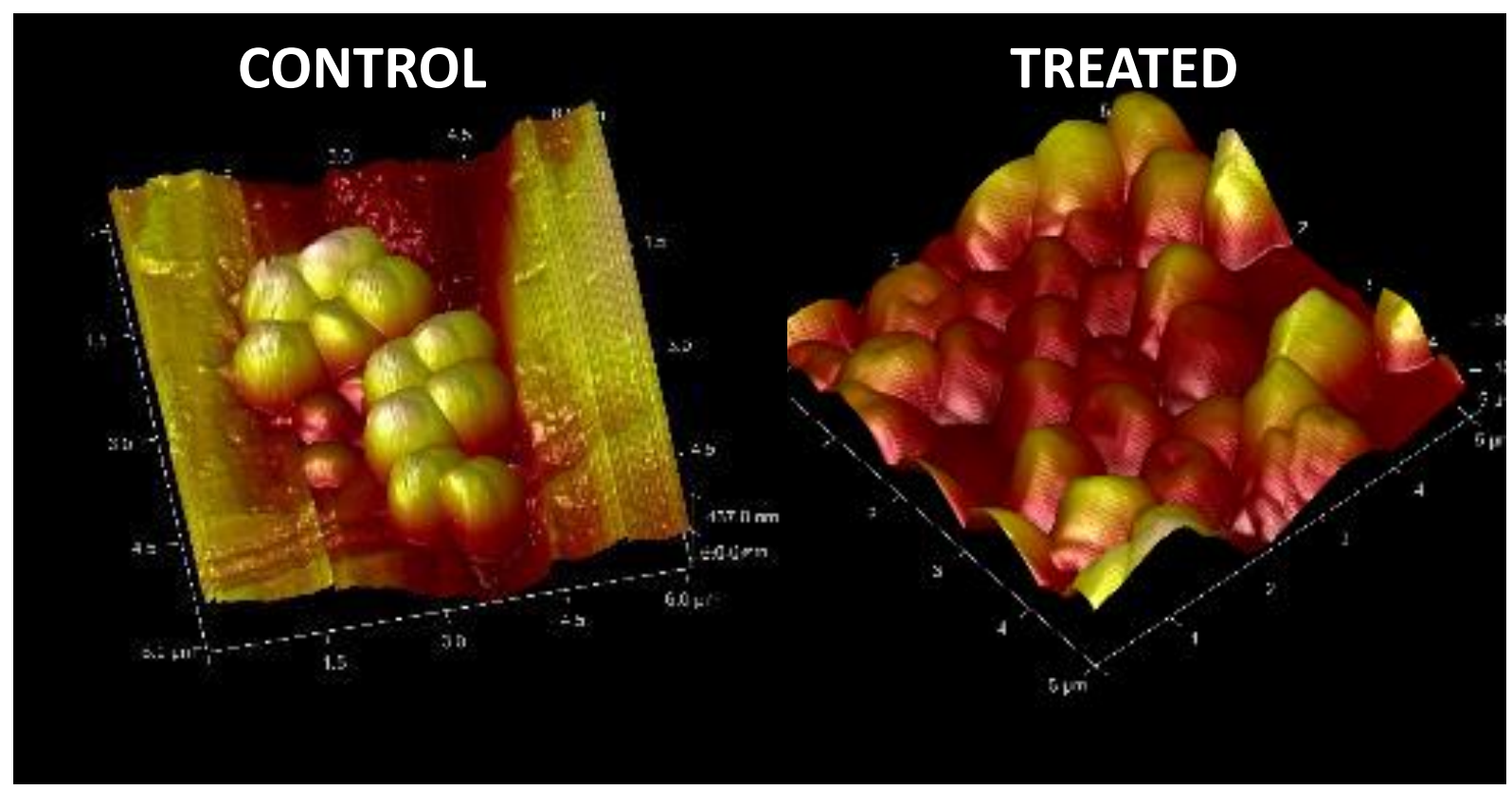

Figure 14: 3D AFM imaging of bacterial killing (MRSA) after a 3 hour-contact with dipcoated Q-PVP-4-days.

Yellow: spherical bacteria, appropriate height (live)

Red: loss of height and perforation of bacteria (dead)

\section{DISCUSSION}

Quaternary ammonium compounds have been known as an antibacterial agent in solution for almost a century (22). Their primary and main use to this date is surface disinfection (23). Their mechanism of action in solution has been already extensively described (24)(25)(26)(27). Because of their efficacy in solution, toxicity thresholds were defined, especially regarding hemolysis (19). Also, there have been efforts to mitigate the risk of cytotoxicity by associating quaternary ammonium compounds with various molecules in solution (28). However, quaternary ammonium polymers (QAP) in solution are of limited use for implantable devices as they do not permit any lasting antibacterial effect on surfaces due to rapid dispersion of the polymers. The immobilization of antibacterial polymers on implantable surfaces led to the discovery of various techniques that allowed the use of smaller polymer quantities with local 
efficacy and ideally little to no leaching, reducing the risk of systemic toxicity (9)(16). Most of these techniques are assimilated to either a "grafting to" or a "grafting from" strategy (10). Among "grafting to" anchors, silanes nowadays stand as one of the most easily mastered standard (29). Silane anchors can either be integrated into the polymer of interest forming a ready-to-graft polymer or they may be used in the setting of an intermediate step before adding the polymer onto the surface, the latter being the most conventional strategy (silane spacer) (30). In both cases, covalent grafting occurs and provides a strong attachment onto various surfaces displaying hydroxyl groups. In our study, we opted for a ready-to-use quaternized polyvinylpyridine polymer covalently grafted on pure titanium, which is a gold standard metal in terms of biocompatibility(31). The synthesis was carried out in an methanolic solution in a single step, which considerably simplified other processes for quaternized polyvinylpyridine. The adjunction of polyethylene glycol (PEG) into the reaction was performed because PEG is classically described as an anti-adhesive and bacterial inhibiting agent (32). Also, PEG-derived polymers such as polyethylene glycol methyl ether methacrylate (PEGMA) and hydroxyethyl methacrylate (HEMA have the reputation to be biocompatible and can render quaternized polyvinylpyridine biocompatible once incorporated as a copolymer (33). Though Allison et al. worked on polymers in solution, we speculated that replacing 1-bromobutane with PEG in the initial synthesis would provide a polymer with excellent biocompatibility when grafted on titanium. Alas, this had the complete opposite effect and Q-PVP-PEG displayed the lowest viable cells at 72h (MTT-assay), regardless of the cell line. Progressively, it became obvious that despite the reputation of quaternized PVP of being cytotoxic and not biocompatible, fine changes in quaternization rates by modulation of reaction time thus affecting surface cationic density, would reveal a biocompatible/antibacterial window. Therefore, candidate polymers of interest were selected: Q-PVP-iodo with no butyl group, Q-PVP-36h, Q-PVP-2 days and QPVP-4 days. Q-PVP-iodo increased MC3T3 cell viability at $72 \mathrm{~h}$, which may be of interest to promote bone adhesion on modified surfaces. Besides, these findings were not found between Q-PVP-iodo and L929. The implied mechanism remains to be proven. Furthermore, the four other polymer solutions displayed gradually increasing $\frac{N^{+}}{N}$ ratios with an inverse correlation between biocompatibility and antibacterial activity. All of them except Q-PVP-iodo exceeded the threshold for bactericidal activity described by Kugler et al. (16). However, it seemed that above $10^{15}$ charges $/ \mathrm{cm}^{2}$, bactericidal activity did not follow an on/off rule but most likely a continuous increase in efficacy. Indeed, in this study, in the most stringent conditions (i.e regularly enriched in vitro MRSA biofilm model), Q-PVP-4 days dip-coated surfaces did best. 
In our opinion, two main reasons account for this: 1) it had the highest achievable $\frac{N^{+}}{N}$ ratio in our setting 2) the coating thickness was increased. Yet these findings disregard the fact that QPVP-4 days decreased both tested cell line viabilities close to the critical viability threshold (70\%). Following L929 and MC3T3 MTT survival assessment, Q-PVP-2 days demonstrated the best compromise in terms of preliminary biocompatibility testing (L929 and MC3T3 survival) and surface cationic density (systematically above $10^{15}$ cations $/ \mathrm{cm}^{2}$ ). Therefore, we postulate that the best compromise of viability and antibacterial activity would be using QPVP-2 days as a ready-to-use and covalently graftable coating. Regarding coating thickness, it seemed to be an important factor to modulate as it impacted leaching severity. The leaching mechanism in this study depended on coating thickness and probably butyl group lengths. A longer carbon-chain may have decreased hydrolysis by distilled water of the silane bond from the surface. In this study, Only SLSC plates in distilled water demonstrated leaching that was significant enough to drop below the biocidal effect threshold $\left(10^{15}\right.$ charges $\left./ \mathrm{cm}^{2}\right)$. Thicker coatings may also prevent water from interacting with the titanium-silane bond. Therefore, optimizing coating thickness and cationic density through reaction time modulation is expected to lead to durable grafting and persistence in vivo, which should be confirmed in animal studies.

This is the first AFM study visually demonstrating the 3D killing effect of surfaces covalently grafted with high-density QAP. The displayed effects were perforation and shrinking dramatically impacting the external shape of bacteria (MRSA). In contrast, AFM studies on QAP in solution raise the issue of the external stress (AFM tip) that may enhance QAP action and eventually destroy bacterial cell membranes (18). In this study, high cationic density was sufficient to cause bacterial cell perforation and death.

\section{Limitations of the study:}

We have not explained why PEGylated polymers performed poorly in terms of cell viability. There was a seemingly contradictory result concerning fluorescein test measurements regarding SLSC with Q-PVP-4 days compared with Q-PVP-B36h. It was expected that Q-PVP-4 days would display a higher absorbance, which appeared to be systematically the opposite. This warrants further investigation too. Also, biocompatibility studies were performed on spincoated surfaces while biofilm studies relied on dip-coated samples, which may introduce a bias artificially maintaining a high viability due to thinner surfaces. 
CONCLUSION:

3578

5579 Partially quaternized and silanized polyvinylpyridine in solution, especially when synthesized

7580 in 48 hours, may represent a good compromise of biocompatibility and bactericidal activity 8

9581 against MRSA when grafted on titanium. If ultimately confirmed in vivo, these findings could 10

582 pave the way for easier synthesis and grafting to render surfaces permanently biocidal and 12583 biocompatible. 


\section{ACKNOWLEDGMENTS:}

Houssam Bouloussa, MD, MS (Conceptualization, Data curation, Formal analysis, Funding acquisition, investigation, methodology, Software, Writing original draft), Azzam SalehMghir, PhD (Conceptualization, Data curation, Formal analysis, Investigation, Methodology, Project administration, Resources, Supervision, Validation, Visualization), Claire Valotteau, PhD (Data curation, Formal analysis, investigation, methodology, Software, Resources, Visualization), Chahrazad Cherifi, PhD (Data curation, Formal analysis, investigation, methodology, Software, Resources, Visualization), Narjes Hafsia, PhD (Data curation, Formal analysis, investigation, methodology, Software, Resources, Visualization), Martine CohenSolal, MD, PhD (Methodology, Project Administration, Resources, Supervision), Charles Court, MD, PhD (Project Administration), Anne-Claude Crémieux, MD, PhD (Conceptualization, Formal analysis, Funding Acquisition, Investigation, Methodology, Project Administration, Resources, Supervision, Validation, Visualization, Review-editing ), Vincent Humblot, PhD (Conceptualization, Data curation, Formal analysis, Investigation, Methodology, Project Administration, Resources, Software, Supervision, Validation, Visualization, Writing - review \& editing).

We would like to thank Pr. Philippe Hernigou for his logistic help.

\section{FUNDING STATEMENT:}

643 This work was supported by IMEA - Fondation Internationale Léon Mba and Société Française 644 de Chirurgie Orthopédique. The funders had no role in study design, data collection and

\section{DISCLOSURE:}

Houssam Bouloussa, MD, MS declares that he is co-inventor of issued patent US US10238110B2 and owns stocks from DeBogy Molecular, Inc. (current assignee). 


\section{REFERENCES}

1. Tsaras G, Osmon DR, Mabry T, Lahr B, St Sauveur J, Yawn B, et al. Incidence, secular trends, and outcomes of prosthetic joint infection: a population-based study, olmsted county, Minnesota, 1969-2007. Infect Control Hosp Epidemiol. 2012 Dec;33(12):1207-12. 2. Kurtz S, Ong K, Lau E, Mowat F, Halpern M. Projections of primary and revision hip and knee arthroplasty in the United States from 2005 to 2030. J Bone Joint Surg Am. 2007 Apr;89(4):780-5.

3. Kurtz SM, Lau E, Watson H, Schmier JK, Parvizi J. Economic burden of periprosthetic joint infection in the United States. J Arthroplasty. 2012 Sep;27(8 Suppl):615.e1.

4. Lewis K. Persister cells, dormancy and infectious disease. Nat Rev Microbiol. 2007 Jan;5(1):48-56.

5. Gries CM, Kielian T. Staphylococcal Biofilms and Immune Polarization During Prosthetic Joint Infection. J Am Acad Orthop Surg. 2017 Feb;25 Suppl 1:S20-4.

6. Donlan RM. Biofilms: microbial life on surfaces. Emerg Infect Dis. 2002 Sep;8(9):881-90.

7. Urish KL, DeMuth PW, Kwan BW, Craft DW, Ma D, Haider H, et al. Antibiotictolerant Staphylococcus aureus Biofilm Persists on Arthroplasty Materials. Clin Orthop. 2016 Jul;474(7):1649-56.

8. Moyad TF, Thornhill T, Estok D. Evaluation and management of the infected total hip and knee. Orthopedics. 2008 Jun;31(6):581-8; quiz 589-90.

9. Tiller JC, Liao CJ, Lewis K, Klibanov AM. Designing surfaces that kill bacteria on contact. Proc Natl Acad Sci U S A. 2001 May 22;98(11):5981-5.

10. Chouirfa H, Bouloussa H, Migonney V, Falentin-Daudré C. Review of titanium surface modification techniques and coatings for antibacterial applications. Acta Biomater. 2019 Jan 1;83:37-54.

11. Muxika A, Etxabide A, Uranga J, Guerrero P, de la Caba K. Chitosan as a bioactive polymer: Processing, properties and applications. Int J Biol Macromol. 2017 Dec;105(Pt 687 2):1358-68.

688 12. Pugachev MV, Shtyrlin NV, Sapozhnikov SV, Sysoeva LP, Iksanova AG, Nikitina $689 \mathrm{EV}$, et al. Bis-phosphonium salts of pyridoxine: the relationship between structure and 
antibacterial activity. Bioorg Med Chem. 2013 Dec 1;21(23):7330-42.

13. Tashiro T. Antibacterial and Bacterium Adsorbing Macromolecules. Macromol Mater Eng. 2001;286(2):63-87.

14. Madaan P, Tyagi VK. Quaternary Pyridinium Salts: A Review. J Oleo Sci. 2008;57(4):197-215.

15. Budhathoki-Uprety J, Peng L, Melander C, Novak BM. Synthesis of Guanidinium Functionalized Polycarbodiimides and Their Antibacterial Activities. ACS Macro Lett. 2012 Mar 20;1(3):370-4.

16. Kügler R, Bouloussa O, Rondelez F. Evidence of a charge-density threshold for optimum efficiency of biocidal cationic surfaces. Microbiol Read Engl. 2005 May;151(Pt 5):1341-8.

17. Gristina AG, Naylor P, Myrvik Q. Infections from biomaterials and implants: a race for the surface. Med Prog Technol. 1988 1989;14(3-4):205-24.

18. Crismaru M, Asri LATW, Loontjens TJA, Krom BP, de Vries J, van der Mei HC, et al. Survival of Adhering Staphylococci during Exposure to a Quaternary Ammonium Compound Evaluated by Using Atomic Force Microscopy Imaging ${ }^{\nabla}$. Antimicrob Agents Chemother. 2011 Nov;55(11):5010-7.

19. Stratton TR, Rickus JL, Youngblood JP. In vitro biocompatibility studies of antibacterial quaternary polymers. Biomacromolecules. 2009 Sep 14;10(9):2550-5.

20. Vallée A, Humblot V, Al RH, Boujday S, Pradier CM. BSA adsorption on aliphatic and aromatic acid SAMs: investigating the effect of residual surface charge and sublayer nature. Colloids Surf B Biointerfaces. 2013 Sep;109:136-42.

21. 14:00-17:00. ISO 11137-2:2013 [Internet]. ISO. [cited 2019 May 29]. Available from: http://www.iso.org/cms/render/live/en/sites/isoorg/contents/data/standard/06/24/62442.html 22. Domagk, G. A new class of disinfectant. Dtsch Med Wochenschr. 1935;61:829-32. 23. Sykes G. Disinfection and Sterilization. Disinfect Steriliz [Internet]. 1958 [cited 2019 May 28]; Available from: https://www.cabdirect.org/cabdirect/abstract/19592701914 24. Timofeeva L, Kleshcheva N. Antimicrobial polymers: mechanism of action, factors of activity, and applications. Appl Microbiol Biotechnol. 2011 Feb 1;89(3):475-92.

25. Siedenbiedel F, Tiller JC. Antimicrobial Polymers in Solution and on Surfaces: Overview and Functional Principles. Polymers. 2012 Jan 9;4(1):46-71.

26. Denyer SP. Mechanisms of action of antibacterial biocides. Int Biodeterior Biodegrad. 1995 Oct 1;36(3):227-45.

27. Russell AD. The mechanism of action of some antibacterial agents. Prog Med Chem. 
724 1969;6:135-99.

1725 28. Stratton TR, Applegate BM, Youngblood JP. Effect of steric hindrance on the

3
4 26 properties of antibacterial and biocompatible copolymers. Biomacromolecules. 2011 Jan

5727 10;12(1):50-6.

7728 29. Tiller JC, Lee SB, Lewis K, Klibanov AM. Polymer surfaces derivatized with

9729 poly(vinyl-N-hexylpyridinium) kill airborne and waterborne bacteria. Biotechnol Bioeng. 